\title{
SINKRONISASI KURIKULUM JURUSAN AKUNTANSI DAN KEUANGAN LEMBAGA DI SMK NU 01 KENDAL
}

\author{
Dwi Astarani Aslindar'), Shofiatul Mila1), Rizki Ridhasyah') \\ 1)Program Studi Akuntansi, Fakultas Ekonomika dan Bisnis, Universitas Selamat Sri, Kendal, Jawa Tengah, Indonesia \\ Corresponding author : Dwi Astarani Aslindar \\ E-mail : dwiastarani@gmail.com
}

Diterima 10 November 2021, Disetujui 22 November 2021

\begin{abstract}
ABSTRAK
Kurikulum SMK dibuat agar peserta didik siap langsung masuk ke dunia kerja. Maka dari itu diperlukan pengembangan dan penyesuaian kurikulum sesuai dengan kebutuhan dunia usaha/dunia industri. Hal ini juga dibutuhkankan oleh SMK NU 01 Kendal jurusan akuntansi dan keuangan Lembaga karena kurikulum yang digunakan belum memberikan pengembangan keilmuan akuntansi, teknologi dan kesesuaian dengan kebutuhan dunia usaha/dunia industry (DU/DI). Tim pengabdian Program Studi Akuntansi Universitas Selamat Sri menaggapi positif dengan mengadakan kegiatan pengabdian masyarakat tentang sinkronisasi kurikulum pada jurusan akuntansi dan keuangan Lembaga SMK NU 01 Kendal. Tujuan kegiatan pengabdian masyarakat ini adalah mengembangkan kurikulum sesuai dengan KKNI Level 2 yang berbasis pengembangan bidang ilmu akuntansi, memberikan realisasi konsep link and match antara SMK dan dunia usaha/dunia industry (DU/DI) dan berorientasi pada pengembangan teknologi. Kegiatan pengabdian dengan metode ceramah, tutorial, diskusi dan simulasi penyusunan kurikulum memberikan pemahaman dan keilmuan tentang perkembangan akuntansi, perkembangan teknologi dan kebutuhan Dunia Usaha Dunia Industri (DU/DI) untuk dapat diterapkan pada jurusan akuntansi dan keuangan lembaga di SMK NU 01 Kendal.
\end{abstract}

Kata kunci: sinkronisasi kurikulum; jurusan akuntansi dan keuangan lembaga; SMK NU 01 Kendal

\begin{abstract}
The SMK curriculum is designed so that students are ready to enter the world of work. Therefore, it is necessary to develop and adjust the curriculum according to the needs of the business world/industrial world. This is also needed by SMK NU 01 Kendal majoring in accounting and institutional finance because the curriculum used does not provide scientific development of accounting, technology and conformity to the needs of the business world/industrial world (DU/DI). The service team for the Accounting Study Program at Selamat Sri University responded positively by holding community service activities regarding curriculum synchronization in the accounting and finance department of the SMK NU 01 Kendal. The purpose of this community service activity is to develop a curriculum in accordance with KKNI Level 2 which is based on the development of the field of accounting science, provides the realization of the link and match concept between SMK and the business world/industrial world (DU/DI) and is oriented towards technology development. Service activities with lecture methods, tutorials, discussions and curriculum preparation simulations provide understanding and knowledge of accounting developments, technological developments and the needs of the Industrial World Business World (DU/DI) to be applied to accounting and institutional finance departments at SMK NU 01 Kendal.
\end{abstract}

Keywords: curriculum synchronization; department of accounting and institutional finance; SMK NU 01 Kendal

\section{PENDAHULUAN}

Pendidikan menengah kejuruan merupakan pendidikan yang terdapat pada jenjang pendidikan menengah untuk mengembangkan kemampuan peserta didik dalam melaksanakan jenis pekerjaan tertentu dalam rangka menyiapkan peserta didik untuk memasuki lapangan pekerjaan. Sekolah Menengah Kejuruan (SMK) sebagai pelaku pendidikan menengah kejuruan harus menyelenggarakan

program-program

pendidikan keahlian sesuai dengan kebutuhan dunia usaha/ dunia insustri (DU/DI) yang tercermin dalam kurikulumnya.

Kurikulum SMK dibuat agar peserta didik siap langsung masuk ke dunia kerja. Kurikulum SMK dibuat untuk mendukung tujuan pendidikan menengah kejuruan sesuai Undang-Undang Nomor 20 Tahun 2003 yaitu menyiapkan peserta didik agar menjadi 
manusia produktif, mampu bekerja mandiri, mengisi lowongan pekerjaan yang ada sebagai tenaga kerja tingkat menengah sesuai dengan kompetensi dalam program keahlian yang dipilihnya, menyiapkan peserta didik agar mampu memilih karir, ulet dan gigih dalam berkompetensi, beradaptasi di lingkungan kerja dan mengembangkan sikap profesional dalam bidang keahlian yang diminatinya, membekali peserta didik dengan ilmu pengetahuan, teknologi dan seni agar mampu mengembangkan diri di kemudian hari baik secara mandiri maupun melalui jenjang pendidikan yang lebih tinggi, dan membekali peserta didik dengan kompetensi-kompetensi yang sesuai dengan program keahlian yang dipilih.

Pada kenyataannya tujuan pendidikan menengah kejuruan sesuai Undang-Undang Nomor 20 Tahun 2003 belum dapat tercapai secara maksimal. Berdasarkan data Badan Pusat Statistik (BPS) bahwa menurut pendidikan yang ditamatkan, dari 9,77 juta angka pengangguran terbuka, 13,55 persen lulusan SMK, 9,86 persen lulusan SMA, 8,08 persen lulusan diploma, 7,35 persen lulusan universitas, 6,46 persen lulusan SMP, dan 3,61 persen lulusan SD. (kompas.com, 2020). Lulusan SMK tidak banyak terserap di dunia kerja dikarenakan kalah bersaing di bursa kerja akibat tuntutan dunia kerja yang mengharuskan memiliki kompetensi keahlian praktis yang kompetitif.

Kabupaten Kendal merupakan salah satu kabupaten di Jawa Tengah yang cukup memiliki banyak Sekolah Menengah Kejuruan (SMK). Hal ini mengingat bahwa di Kabupaten Kendal memiliki Kawasan Industri Kendal (KIK) yang membutuhkan banyak tenaga kerja yang memiliki keahlian dan siap bekerja. Berdasarkan statistic potensi SMK pada data Dinas Penanaman Modal dan Pelayanan Terpadu Satu Pintu Provinsi Jawa Tengah, diketahui bahwa jumlah SMK di Kabupaten Kendal adalah 50 sekolah. SMK NU 01 Kendal adalah salah satu SMK di Kabupaten Kendal yang memiliki program keahlian antara lain Akuntansi dan Keuangan Lembaga, Bisnis Daring dan Pemasaran, Otomatisasi dan Tata Kelola Perkantoran, Tata Busana, Tata Boga, Teknik Kendaraan Ringan dan Otomotif dan Rekayasa Perangkat Lunak. Salah satu jurusan yang memiliki peminat cukup banyak di SMK NU 01 Kendal adalah jurusan akuntansi dan keuangan lembaga. Lulusan dari jurusan akuntansi dan keuangan lembaga SMK NU 01 Kendal disiapkan untuk bekerja antara lain sebagai pemegang buku perusahaan, kasir/ teller, penyusunan laporan keuangan pada usaha jasa maupun usaha dagang, administrasi gudang, konsultan pajak, operator komputer, asisten akuntan dan beberapa lulusan juga melanjutkan ke perguruan tinggi.

Lulusan jurusan akuntansi dan keuangan lembaga SMK NU 01 Kendal belum terserap dalam dunia kerja secara maksimal. Lulusan belum terserap dengan maksimal karena kompetensi keahlian praktis yang dimiliki belum sesuai dengan kebutuhan dunia usaha/ dunia industry. Hal ini menunjukkan bahwa kurikulum yang diterapkan di SMK NU 01 Kendal belum memberikan pengembangan keilmuan akuntansi, teknologi dan kesesuaian dengan kebutuhan dunia usaha/dunia industry (DU/DI). Pengembangan dan penyesuaian kurikulum merupakan suatu kebutuhan sebagai langkah penyelarasan kurikulum sehingga ada keserasian antara hasil Pendidikan dan kebutuhan dunia usaha/dunia industry (DU/DI). Untuk itu, SMK dituntut untuk dapat bermitra dengan dunia usaha/dunia industry dan perguruan tinggi dalam mengembangkan kualitas pendidikan di SMK agar tidak tumpang tindih pembelajaran dan sesuai dengan kompetensi KKNI level 2 yang sudah diterapkan oleh pemerintah.

Kebutuhan akan pengembangan dan penyesuaian kurikulum ditanggapi positif oleh Universitas Selamat Sri, sebagai satu-satunya perguruan tinggi di Kabupaten Kendal yang memiliki program studi akuntansi. Berdasarkan analisis situasi yang ada di SMK NU 01 Kendal jurusan akuntansi dan keuangan lembaga, melatarbelakangi tim pengabdian masyarakat Program Studi Akuntansi Universitas Selamat Sri untuk mengadakan kegiatan pengabdian masyarakat tentang sinkronisasi kurikulum jurusan akuntansi dan keuangan Lembaga SMK NU 01 Kendal. Sinkronisasi kurikulum dilakukan sebagai upaya mengembangkan kurikulum sesuai dengan KKNI Level 2 yang berbasis pengembangan bidang ilmu akuntansi, memberikan realisasi konsep link and match antara SMK dan dunia usaha/dunia industry (DU/DI) dan berorientasi pada pengembangan teknologi. Sinkronisasi kurikulum diharapkan dapat memberikan pemahaman dan keilmuan tentang perkembangan akuntansi, perkembangan teknologi dan kebutuhan Dunia Usaha / Dunia Industri (DU/DI) untuk dapat diterapkan pada jurusan akuntansi dan keuangan lembaga di SMK NU 01 Kendal sehingga menghasilkan lulusan SMK yang memiliki keahlian kompetensi praktis sesuai dengan kebutuhan dunia usaha/dunia industry (DU/DI).

\section{METODE}

Sinkronisasi kurikulum Jurusan Akuntansi dan Keuangan Lembaga SMK NU 01 
Kendal dilaksanakan dengan guru-guru produktif akuntansi dan keuangan lembaga sebagai sasaran dalam kegiatan ini. Pemilihan guru produktif sebagai sasaran dalam kegiatan dengan pertimbangan bahwa guru produktif sebagai pelaksana dari pemberian muatan pembelajaran sesuai kurikulum. Selain itu guru produktif memiliki keahlian praktis yang memadai pada bidang ilmunya, mampu menyelenggarakan pembelajaran yang relevan dengan kompetensi yang dibutuhkan oleh dunia kerja, mampu merancang pembelajaran baik di sekolah maupun di dunia usaha dan industri.

Kegiatan Sinkronisasi Kurikulum Jurusan Akuntansi dan Keuangan Lembaga SMK NU 01 Kendal dilakukan dengan tahapan Perencanaan, Perijinan dan Pelaksanaan. Tahapan perencanaan kegiatan Sinkronisasi Kurikulum Jurusan Akuntansi dan Keuangan Lembaga Di SMK NU 01 Kendal dilakukan melalui beberapa tahapan kegiatan. Tahap pertama mengajukan kerjasama dengan mitra dilakukan melalui penandatanganan surat kerjasama antara tim pengabdian masyarakat Program Studi Akuntansi Universitas Selamat Sri Kendal dengan Kepala SMK NU 01 Kendal. Tahap kedua menyusun jadwal untuk menentukan pembagian waktu dari mulai tahap awal sampai akhir dengan berkoordinasi dengan Kepala SMK NU 01 Kendal dalam pelaksanaan kegiatan. Tahap ketiga menentukan tempat pelaksanaan kegiatan melalui koordinasi dengan Kepala SMK NU 01 Kendal dengan mempertimbangkan jumlah peserta kegiatan yang akan menghadiri kegiatan sinkronisasi. Tahap keempat menyusun acara sedemikian rupa sehingga semua materi bisa tersampaikan dan tujuan dari kegiatan ini bisa tercapai. Tahap kelima menyiapkan materi yang akan disampaikan dalam kegiatan pengabdian. Sekolah menyiapkan draft yang terdiri atas dokumendokumen kurikulum. Draft kurikulum diberikan oleh pengisi acara dalam hal ini diberikan kepada tim pengabdian Program Studi Akuntansi Universitas Selamat Sri dan perwakilan dari DU/DI. Tim pengabdian Program Studi Akuntansi Universitas Selamat Sri dan perwakilan dari DU/DI juga diminta untuk menyiapkan draft Standar Kompetensi yang berlaku di DU/DI dengan mamasukkan aspek perkembangan ilmu akuntansi dan teknologi.

Tahap setelah perencanaan adalah tahap perijinan. Perijinan terkait dengan penggunaan lokasi pengabdian yaitu ruang laboratorium jurusan akuntansi dan keuangan lembaga SMK NU 01 Kendal. Tim melakukan koordinasi dengan Kepala SMK NU 01 Kendal terkait perijinan penggunaan ruang di SMK NU
01 Kendal sebagai tempat pengabdian dengan tetap memperhatikan protokol kesehatan seperti penggunaan masker dan hand sanitizer pada saat pelaksanaan kegiatan. Tim juga melakukan koordinasi dengan ketua jurusan akuntansi dan keuangan lembaga SMK NU 01 Kendal kaitannya dengan persiapan laboratorium jurusan akuntansi dan keuangan lembaga sebagai tempat kegiatan pengabdian.

Tahap terakhir adalah tahap pelaksanaan. Kegiatan dilaksanakan pada hari Senin, tanggal 13 September 2021 pukul 08.00 sampai 12.00 ruang laboratorium jurusan akuntansi dan keuangan Lembaga SMK NU 01 Kendal. Kegiatan yang dilakukan adalah Sinkronisasi Kurikulum Jurusan Akuntansi Dan Keuangan Lembaga Di SMK NU 01 Kendal. Pelaksanaan kegiatan sinkronisasi juga melibatkan perwakilan Dunia Usaha Dunia Industri (DU/DI). Pelaksanaan dilakukan dengan metode ceramah, tutorial, diskusi, simulasi penyusunan pengembangan kurikulum. Masing-masing pihak memaparkan materi dan memberikan masukan terhadap kurikulum yang sudah ada. Pada tahap penyusunan pengembangan kurikulum dilakukan dengan mengkaji kurikulum yang sudah ada dan memasukkan rekomendasi yang diberikan baik oleh tim pengabdian program studi akuntansi Universitas Selamat Sri maupun dari DU/DI.

\section{HASIL DAN PEMBAHASAN}

Sinkronisasi kurikulum Jurusan Akuntansi dan Keuangan Lembaga SMK NU 01 Kendal dilakukan dengan metode ceramah, tutorial, diskusi dan simulasi. Kegiatan yang pertama yang melalui metode ceramah, peserta kegiatan sinkronisasi kurikulum diberikan pemahaman mengenai pentingnya kegiatan sinkronisasi kurikulum yaitu penyesuaian kurikulum antara sekolah dan industry tetapi harus sesuai dengan panduan yang diberikan oleh pemerintah dalam suatu KKNI level 2 . Peserta kegiatan sinkronisasi diberikan gambaran perkembangan bidang ilmu akuntansi, tantangan akuntansi di industry terkait perkembangan revolusi industry 5.0 dengan realisasi konsep link and match antara SMK dan dunia usaha/dunia industry (DU/DI), serta perkembangan teknologi dalam hubungannya dalam pembelajaran akuntansi. Antusiasme terlihat dari berjalannya kegiatan yang dimulai dari narasumber yang memberikan ceramah. 


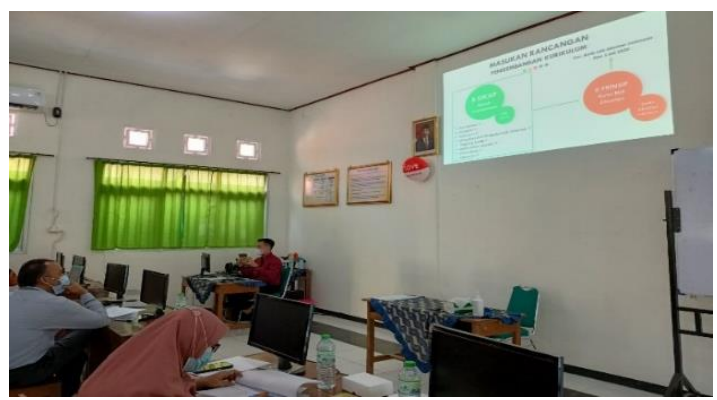

Gambar 1. Pemberian Materi Sinkronisasi

Kegiatan yang kedua, Tim Pengabdian Program Studi Akuntansi Universitas Selamat Sri memberikan tutorial pendampingan langkah - langkah penyusunan kompetensi keahlian yang dimasukkan kedalam materi ajar pada pelajaran akuntansi untuk jurusan akuntansi dan keuangan lembaga serta mengembangkan praktik sesuai dengan kebutuhan Dunia Usaha Dunia Industri (DU/DI).

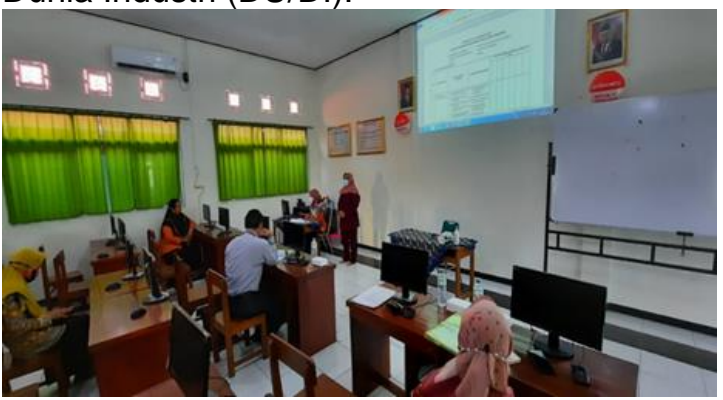

Gambar 2. Tutorial Pengembangan Kurikulum

Kegiatan yang ketiga, peserta sinkronisasi kurikulum berdiskusi dengan tim pengabdian serta perwakilan DU/DI mengenai permasalahan yang dihadapi. Peserta mendiskusikan dan menyampaikan mengenai materi dalam jurusan akuntansi dan keuangan lembaga yang selama ini telah dilakukan. Dari permasalahn yang telah disampaikan dilakukan upaya untuk mereview kurikulum yang telah dilaksanakan dan mempersilahkan untuk memberikan masukan-masukan terkait RPP, Silabus, dan Materi pada jurusan akuntansi dan keuangan lembaga. Masing-masing masukan dijadikan sebagai bahan rekomendasi untuk pengembangan kurikulum.

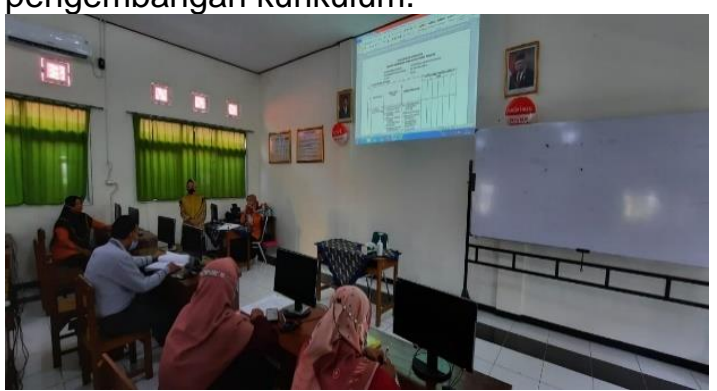

Gambar 3. Masukan Dari Peserta

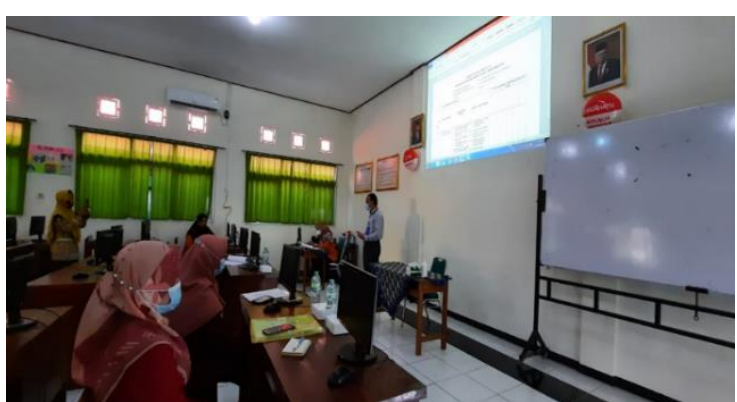

Gambar 4. Masukan dari DU/DI

Kegiatan terakhir, masukan-masukan yang disampaikan baik oleh tim pengabdian maupun perwakilan DU/DI dijadikan sebagai bahan untuk dijadikan sebagai rekomendasi pengembangan kurikulum. Dari hasil masukan tersebut dengan tetap memperhatikan panduan yang diberikan oleh pemerintah dalam suatu KKNI level 2 maka dilakukan simulasi dalam penyusunan kurikulum jurusan akuntansi dan keuangan lembaga yang telah disesuaikan dengan kebutuhan DU/DI.

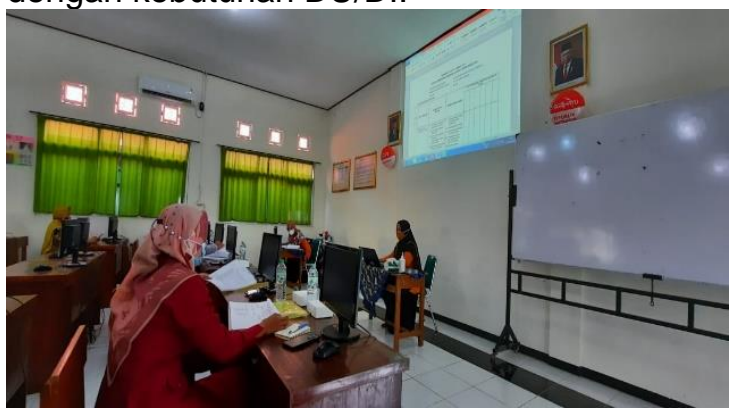

Gambar 5. Simulasi Pengembangan Kurikulum

Berdasarkan kegiatan sinkronisasi kurikulum yang dilakukan oleh tim pengabdian maka diperoleh pengembangan kurikulum berbasis pengembangan bidang ilmu akuntansi, realisasi konsep link and match antara SMK dan dunia usaha/dunia industry (DU/DI) dan berorientasi pada pengembangan teknologi. Berdasarkan hasil sinkronisasi diperoleh kurikulum jurusan akuntansi dan keuangan lembaga yaitu RPP dan Silabus diarahkan pada upaya peningkatan pemahaman ilmu akuntansi dan perkembangannya dengan memperbanyak bobot untuk latihan, mengubah bobot praktik sesuai dengan kebutuhan industri dengan tetap berpedoman pada $\mathrm{KKNI}$ level 2, memasukkan materi kuliah umum dengan mengundang pengajar dari dunia industry atau dari Perguruan Tinggi agar mendapat ilmu dan pemahaman bidang akuntansi yang lebih banyak, menetapkan standar kompetensi siswa dalam penggunaan komputerisasi di bidang akuntansi, mengoptimalkan kegiatan prakerin atau praktik kerja industry sehingga siswa benar-benar memperoleh pengalaman dalam DU/DI. 
Kegiatan sinkronisasi kurikulum akan menghasilkan kurikulum yang berbasis pengembangan bidang ilmu akuntansi dan pengembangan teknologi serta realisasi konsep link and match antara SMK dan dunia usaha/dunia industry (DU/DI) melalui kerjasama antara sekolah dengan Dunia Usaha Dunia Industri (DU/DI), melakukan kegiatan berupa forum diskusi yang rutin antara sekolah, perguruan tinggi dan DU/DI dalam hal pengembangan akuntansi di DU/DI serta sekolah dengan Perguruan Tinggi dan DU/DI melakukan evaluasi secara rutin terhadap program-program untuk menunjang keberhasilan kurikulum dan keefektifitasannya.

\section{SIMPULAN DAN SARAN}

Kegiatan sinkronisasi kurikulum yang dihadiri oleh guru-guru produktif jurusan akuntansi dan keuangan lembaga SMK NU 01 Kendal berjalan dengan baik dan lancar. Guru mendapatkan pemahaman dan keilmuan tentang perkembangan akuntansi, perkembangan teknologi dan kebutuhan Dunia Usaha Dunia Industri (DU/DI) untuk dapat diterapkan dalam pelaksanaan kurikulum jurusan akuntansi dan keuangan lembaga di SMK NU 01 Kendal. Kegiatan yang diberikan dengan metode ceramah, tutorial, diskusi dan simulasi ditanggapi dengan antusias oleh peserta kegiatan. Melalui kegiatan ini dapat disusun materi pembelajaran dan praktik akuntansi di jurusan akuntansi dan keuangan lembaga SMK NU 01 Kendal sesuai dengan kebutuhan Dunia Usaha Dunia Industri (DU/DI).

Saran dari kegiatan ini adalah perlu dilaksanakan sinkronisasi kurikulum sebagai agenda rutin untuk perbaikan kurikulum sehingga menghasilkan kurikulum yang berkualitas. Selain itu perlu dilibatkan dalam hal ini civitas akademika perguruan tinggi dan pihak DU/DI yang erat kaitannya dengan pengembangan kurikulum yang salah satunya dengan sinkronisasi kurikulum.

\section{UCAPAN TERIMAKASIH}

$\begin{array}{ccc}\text { Tim pengabdian } & \text { Program Studi } \\ \text { Akuntansi } & \text { Universitas } & \text { Selamat Sri }\end{array}$ mengucapkan terima kasih kepada pihak-pihak yang berkontribusi sehingga pelaksanaan kegiatan pengabdian masyarakat dapat berjalan dengan lancar antara lain $\mathrm{dr}$. $\mathrm{Hj}$. Sulistiyowati, M.M selaku Rektor Universitas Selamat Sri, Suprihono Setyawan, S.Kom, M.M. selaku Ketua Lembaga Penelitian dan Pengabdian Masyarakat (LP2M) Universitas Selamat Sri. Selain itu tim juga mengapresiasi dan mengucapkan terima kasih kepada Kepala SMK NU 01 Kendal sebagai mitra untuk bisa bekerjasama dalam pelaksanaan kegiatan sinkronisasi kurikulum dan seluruh guru produktif jurusan akuntansi dan keuangan lembaga SMK NU 01 Kendal yang telah berpartisipasi aktif dalam kegiatan sinkronisasi kurikulum.

\section{DAFTAR RUJUKAN}

Akhriza, T. M., Arifin, S., Syaifulloh, A. 2019. PKM Pengembangan Kurikulum Berbasis Sertifikasi Internasional Untuk SMK Kabupaten Malang. Jurnal IImiah Pengabdian Pada Masyarakat Vol. 2 No. 2 hal $10-21$

http://www.smknu01kendal.sch.id/home/sambu tan_kepala_sekolah diakses 20 September 2021

https://money.kompas.com/read/2020/12/11/14 3242326/jumlah-pengangguran-terusbertambah-paling-banyak-lulusan-smk diakses 20 September 2021

https://web.dpmptsp.jatengprov.go.id/statistik potensi_smk/kabupaten_kendal diakses 20 September 2021

Kurikulum Sekolah Menengah Kejuruan Edisi 2004. Tentang : Landasan, Program dan Pengembangan. Jakarta : Direktorat Dikmenjur

Reksoadmodjo, T.N. 2010. Pengembangan Kurikulum Pendidikan Teknologi dan Kejuruan. Bandung : Refika Aditama

Taufiq, E. 2020. Sinkronisasi Kurikulum Jurusan Akuntansi dan Lembaga Keuangan di SMK Karya Guna Bhakti II. Jurnal Pengabdian Masyarakat TRI PAMAS, Vol. 2 No. 2 hal $72-78$

Undang-Undang Nomor 20 Tahun 2003 tentang Sistem Pendidikan Nasional. Jakarta: Kementerian Pendidikan dan Kebudayaan

Wageyanto. 2013. Sinkronisasi Kurikulum dalam Pencapaian Tujuan Kurikulum Program Keahlian Produksi Grafika SMK Negeri 4 Malang. Jurnal Pendidikan Vol. 1 No. 1 hal. 61-67. ISSN. 2337-7607

Yoto. Kustono, D., Muladi., Wardana. 2013. Partisipasi Masyarakat Industri Dalam Penyusunan Sinkronisasi Kurikulum di SMK. Jurnal Teknik Mesin No. 1 hal 113-126 